\title{
Right Atrial Pseudomyxoma in a Haemodialysis Patient With a Permanent Dialysis Catheter
}

\author{
Ecaterina Berzan ${ }^{\mathrm{a}, \mathrm{b}}$, Aneta Kecler-Pietrzyk ${ }^{\mathrm{a}}$, John Kavanagh ${ }^{\mathrm{a}}$, \\ Niamh Leonard $^{\mathrm{a}}$, Catherine Walla, George J. Mellotte ${ }^{\mathrm{a}}$
}

\begin{abstract}
Right atrial mass related to thrombus or infection is a frequent complication in patients dialysed with permanent catheters. Atrial tumours can present in a similar fashion and despite of satisfactory echographic imaging, it can be misdiagnosed as thrombus or vice versa. We describe the case of a 49-year-old haemodialysis patient who presented with functional small bowel obstruction. A large right atrial mass was noted incidentally during a CT scan of the abdomen and pelvis. The findings on trans-thoracic and transoesophageal echocardiography were suggestive of an atrial myxoma. The patient underwent resection of the mass, which was highly suspicious on gross appearance for neoplasia. Histological examination revealed it to be a well organised thrombus.
\end{abstract}

Keywords: Right atrial mass; Myxoma; Dialysis catheter thrombus

\section{Introduction}

Current clinical guidelines strongly advocate arterio-venous fistula (AVF) as a first choice dialysis access. Despite this, a large proportion of patients with ESKD receive long term dialysis using tunnelled dialysis catheters. Right atrial thrombus related to dialysis catheters is well recognised complication and the mortality rate due to thrombus associated complications reaches $100 \%$ in untreated patients $[1,2]$. In light of this, prompt diagnosis and treatment are vital for good patient outcome.

\footnotetext{
Manuscript accepted for publication October 11, 2012

${ }^{\mathrm{a}}$ Division of Renal Medicine, Trinity Health Ireland, St James's Hospital, Amnch, Trinity College Dublin, Ireland

${ }^{\mathrm{b}}$ Corresponding author: Ecaterina Berzan, Division of Renal Medicine St James Hospital, Dublin 8, Ireland.

Email:ecaterinaberzan@yahoo.com
}

doi: http://dx.doi.org/10.4021/jmc954e

\section{Case Report}

A 49-year-old patient was admitted with clinical signs and symptoms of small bowel obstruction. His past medical history was notable for ESKD and 2 previous cadaveric renal transplants, 15 and 13 years ago respectively. Post transplant course was complicated by chronic allograft nephropathy. The patient had re-commenced haemodialysis (HD) four months prior via a right internal jugular vein tunnelled catheter. A peritoneal catheter was in place with a plan to transfer to peritoneal dialysis. He remained on low dose cyclosporine to minimise the risk of late rejection.

Four months before this presentation, the patient had a trans-thoracic echocardiogram (TTE) prior to permanent catheter insertion, which did not demonstrate any intra- atrial lesion with a structurally and functionally normal heart. Since initiation of HD the patient did not experience any problems related to his vascular access; blood flows on $\mathrm{HD}$ averaged $300-350 \mathrm{mls} /$ minute and $\mathrm{Kt} / \mathrm{V}$ was adequate. He remained in his usual health until the night of admission when he presented with distended painful abdomen, nausea and vomiting.

As a part of clinical evaluation, the patient underwent $\mathrm{CT}$ abdomen and pelvis which incidentally revealed a $4.1 \times$ $2.8 \mathrm{~cm}$ low attenuation filling defect within the right atrium, adherent to the inter-atrial septum, just opposite to the tip of the tunnelled catheter (Fig. 1). TTE revealed a large inhomogeneous mass with echogenisity and echolucency typical of myxoma arising from inter-atrial septum (Fig. 2). The patient was subsequently anti-coagulated with a plan to proceed to sternotomy and cardiotomy for mass removal.

Prior to surgery, the patient developed features of superior vena cava obstruction with poor blood flows from the HD catheter despite therapeutic anti-coagulation. The patient subsequently underwent excision of the right atrial mass. The mass was adherent to the inter-atrial septum necessitating excision of a small rim of right atrial muscle. The defect formed in the atrial wall was repaired with bovine pericardial patch. The dialysis catheter remained intact and was not removed. The intra-operative finding was of an ovoid $3.8 \times 2.5 \mathrm{~cm}$, shaggy mass with papillary surface, grey 


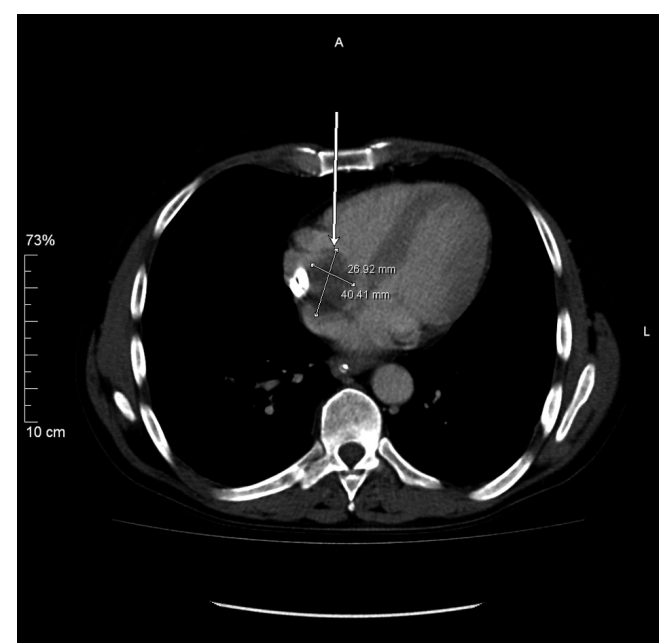

Figure 1. CT abdomen and pelvis revealed a low attenuation filling defect within the right atrium, adherent to the inter-atrial septum, just opposite to the tip of the tunnelled catheter.

and brown attached to the inter-atrial septum on a broad stalk (Fig. 3). Histological examination revealed fibrin layers and aggregates of platelets; characteristic of thrombus with no evidence of tumours cells (Fig. 4).

The patient made an uneventful recovery.

\section{Discussion}

Malignancy is a well recognised complication of immunosuppression. According to tumour registry database, the incidence of lymphoma and skin cancer is increased, while the incidence of solid organ cancer remains unaffected [3]. Cases of cardiac malignancy have been described in patients following bone marrow [4], cardiac [5] and kidney-pancreas transplant [6].

The patient received immunosuppression for 17 years,

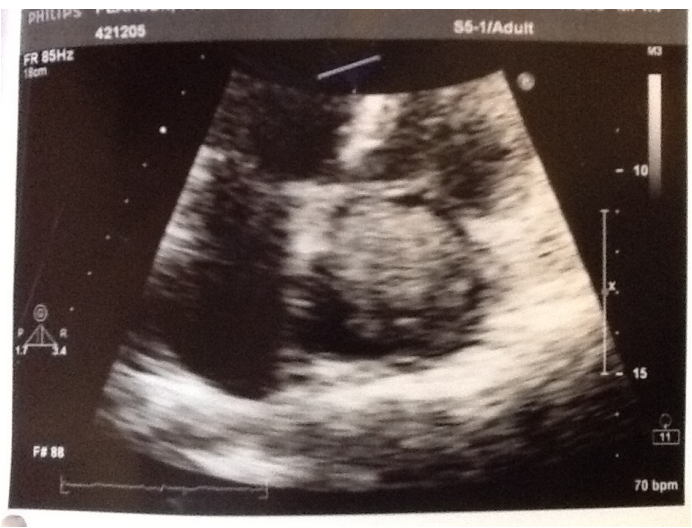

Figure 2. Trans-thoracic echocardiogram revealed a large inhomogeneous mass with echogenisity and echolucency typical of myxoma arising from inter-atrial septum.

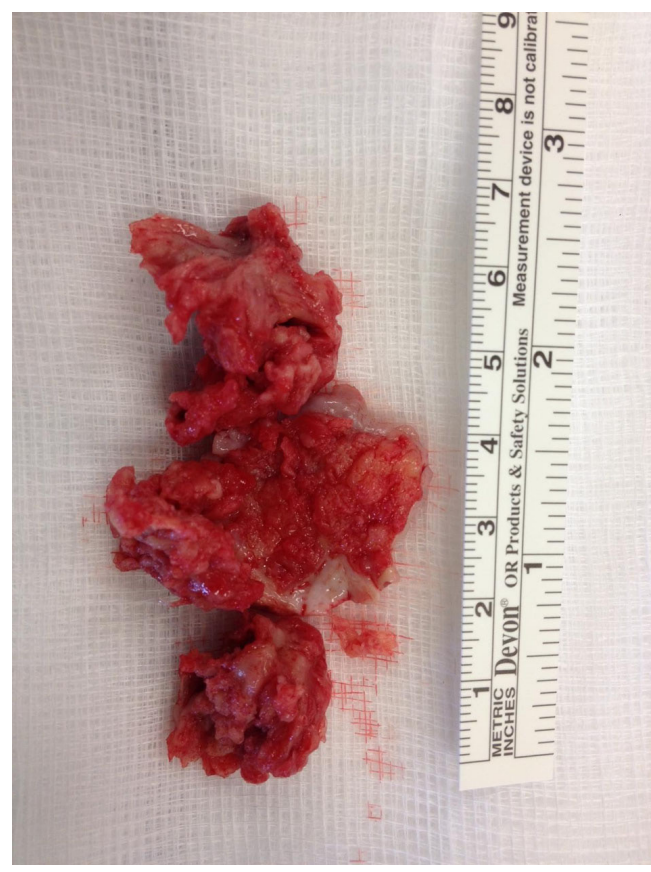

Figure 3. Intra-operative finding of the mass with papillary surface, grey and brown attached to the inter-atrial septum on a broad stalk.

therefore intra-cardiac malignancy was considered in the list of differential diagnoses. Additionally, the echographic findings, the location of the mass and the specificity of attachment were highly suggestive of myxoma. Cardiac tumours are rare with an incidence of $0.001-0.33 \%$. Approximately 25 to $40 \%$ are myxomas and almost a quarter of these originate within the right atrium [7, 8]. Morphologically they can be polypoid, oval or round. They are more common in women, aged between 30 and 60, and approximately $10 \%$ are familial. The symptoms can vary from constitutional to serious complications such as pulmonary embolus and mitral valve obstruction [9].

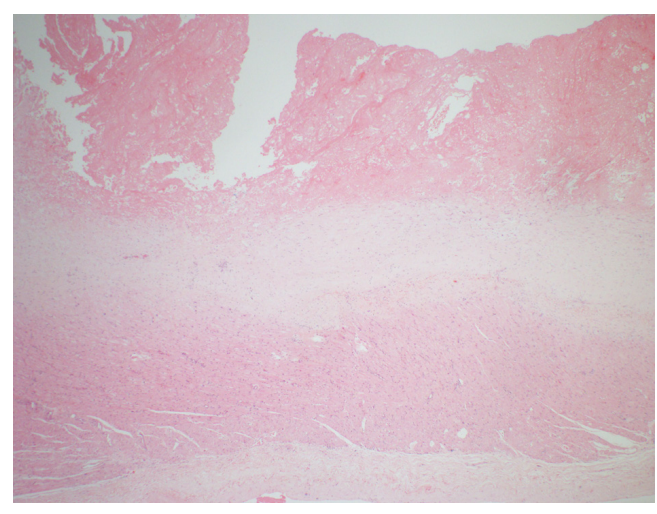

Figure 4. Histological examination revealed fibrin layers and aggregates of platelets; characteristic of thrombus with no evidence of tumours cells. 
The incidence of right atrial myxoma in HD patients with permanent dialysis catheters is not very well described and the incidence is not felt to be higher than the general population. TTE examination usually gives accurate visualisation of the right atrial mass. The patient also underwent TOE for precise location and detailed examination of stalk insertion; information which is invaluable in differentiating between cardiac myxoma and thrombus. Echocardiographic findings, gross appearance of the mass, and its characteristic location were all highly suggestive of right atrial myxoma rather than thrombus.

In contrast to this, right atrial thrombus in HD patients with long term catheter is a well recognised complication $[10,11]$. Right atrial thrombus can also present as a mass and can be easily mis-diagnosed as a myxoma. According to Kurisu et al up to $6 \%$ of catheter-dependent patients have catheter related right atrial thrombus [12]. As many patients remain clinically asymptomatic; the incidence of right atrial thrombus may be even higher, as suggested by Ducatman et al who reported that up to $29 \%$ of HD patients with permanent catheter were found to have intramural thrombi based on post-mortem examination [13]. Pulmonary embolism is the most serious complication of intra-cardiac thrombi with mortality rate as high as $45 \%$ [14]. Our patient received $\mathrm{Cy}$ closporine for over 17 years. Cyclosporine has pro-coagulant properties causing release of von Willebrand Factor and Pselectin from the endothelium and increases Factor VIII levels which may have contributed to thrombus formation [15].

The location of the tip of dialysis catheter has another role to play. As mentioned by Latif $\mathrm{T}$ et al the optimal location for the catheter tip is at the junction of the superior vena cava and right atrium, but not within the atrium itself [16]. This study showed that approximately $12.5 \%$ of the patients with the permcath tip within the right atrium developed thrombus at 1 week interval from insertion. The majority of thrombi were adherent to the interatrial wall, opposite to the tip of catheter, as seen in our patient.

The mechanism of thrombus formation at this site can be explained by the continuous mechanical trauma to the cardiac endothelium by the catheter tip with each cardiac beat. In addition, high blood flow during the haemodialysis adds to the endothelial damage. All above activate the coagulation cascade, which result in clot formation $[17,18]$.

As the diagnosis was uncertain prior to surgery, the patient was fully anti-coagulated with low molecular heparin to minimise the risk of local complications and systemic embolic events. Despite this, HD delivery became problematic due to poor blood flow through the tunnelled catheter.

The optimal management of catheter-associated right atrial thrombus is not well described. It has been suggested previously that management is dependent on the size of the thrombus [19-21]. If thrombus is under $2 \mathrm{~cm}$, removal of the catheter is probably adequate, although Ghani et al suggest systemic anticoagulation for at least 2 weeks prior to cath- eter removal [19]. The most serious complication of a large right atrial thrombus is pulmonary embolism. According to Edward et al the mortality rate from this complication can reach $45 \%$ [12]. In light of this, it is suggested that if the thrombus is larger than $2 \mathrm{~cm}$, an immediate surgical thrombectomy should be considered along with the removal of the catheter $[20,21]$. The selection of patients for surgery is generally based on extent and severity of comorbid disease. Percutaneous mechanical thrombectomy may be a reasonable treatment alternative in high-risk patients [22]. Nevertheless, clear guidelines regarding the management of catheter related thrombus are not available. In our patient, the nature of the mass wasn't clear and although asymptomatic initially, his clinical condition deteriorated rapidly. In this case surgical approach was inevitable and the only correct option.

In conclusion the case highlights that right atrial thrombus related to tunnelled dialysis catheter can be mistaken for right atrial myxoma even with adequate echocardiography. Irrespective of the nature of the mass, surgical resection is indicated for large masses. In light of high mortality rate, clarification of the mass' nature can await histological examination.

\section{References}

1. Little MA, O’Riordan A, Lucey B, Farrell M, Lee M, Conlon PJ, Walshe JJ. A prospective study of complications associated with cuffed, tunnelled haemodialysis catheters. Nephrol Dial Transplant. 2001;16(11):21942200.

2. Rose PS, Punjabi NM, Pearse DB. Treatment of right heart thromboemboli. Chest. 2002;121(3):806-814.

3. Vajdic CM, van Leeuwen MT. Cancer incidence and risk factors after solid organ transplantation. Int J Cancer. 2009;125(8):1747-1754.

4. Baronciani D, Angelucci E, Polchi P, Martinelli F, Mariotti E, Marzocchi A, Longo M, et al. An unusual marrow transplant complication: cardiac myxoma. Bone Marrow Transplant. 1998;21(8):825-827.

5. Yap WW, Bhattacharya K, Pathi V. Left atrial myxoma in transplanted heart. Heart. 2005;91(6):e49.

6. Dadkhah R, Decoodt P. Cardiac myxoma: related to immunosuppression? A case report. Acta Cardiol. 2009;64(4):571-573.

7. Reynen K. Cardiac myxomas. N Engl J Med. 1995;333(24):1610-1617.

8. Burke AP, Virmani R. Cardiac myxoma. A clinicopathologic study. Am J Clin Pathol. 1993;100(6):671-680.

9. Perez de Isla L, de Castro R, Zamorano JL, Almeria C, Moreno R, Moreno M, Lima P, et al. Diagnosis and treatment of cardiac myxomas by transesophageal echocardiography. Am J Cardiol. 2002;90(12):1419-1421.

10. Fincher ME, Caruana RJ, Humphries A, Gross CM, Ru- 
bin JW, Bowen PA. Right atrial thrombus formation following central venous dialysis catheter placement. Am Surg. 1988;54(11):652-654.

11. Kingdon EJ, Holt SG, Davar J, Pennell D, Baillod RA, Burns A, Sweny P, et al. Atrial thrombus and central venous dialysis catheters. Am J Kidney Dis. 2001;38(3):631-639.

12. Kurisu S, Inoue I, Kawagoe T, Ishihara M, Shimatani Y, Hata T, Nakama Y, et al. Right atrial thrombosis as a complication of arrhythmogenic right ventricular cardiomyopathy. Intern Med. 2006;45(7):457-460.

13. Ducatman BS, McMichan JC, Edwards WD. Catheter-induced lesions of the right side of the heart. A one-year prospective study of 141 autopsies. JAMA. 1985;253(6):791-795.

14. Chartier L, Bera J, Delomez M, Asseman P, Beregi JP, Bauchart JJ, Warembourg H, et al. Free-floating thrombi in the right heart: diagnosis, management, and prognostic indexes in 38 consecutive patients. Circulation. 1999;99(21):2779-2783.

15. Nayak SG, Satish R. Extensive cerebral venous thrombosis in a renal allograft recipient. Saudi J Kidney Dis Transpl. 2008;19(1):90-93.

16. Latif T, Steiman DM, Gagaoudakis P. Massive right atrial thrombosis due to Hickman catheter requiring open heart surgery--a case report. Angiology. 2001;52(6):425428.
17. Timsit JF, Farkas JC, Boyer JM, Martin JB, Misset B, Renaud B, Carlet J. Central vein catheter-related thrombosis in intensive care patients: incidence, risks factors, and relationship with catheter-related sepsis. Chest. 1998;114(1):207-213.

18. Forauer AR, Theoharis C. Histologic changes in the human vein wall adjacent to indwelling central venous catheters. J Vasc Interv Radiol. 2003;14(9 Pt 1):11631168.

19. Ghani MK, Boccalandro F, Denktas AE, Barasch E. Right atrial thrombus formation associated with central venous catheters utilization in hemodialysis patients. Intensive Care Med. 2003;29(10):1829-1832.

20. Kinney EL, Wright RJ. Efficacy of treatment of patients with echocardiographically detected right-sided heart thrombi: a meta-analysis. Am Heart J. 1989;118(3):569573.

21. Stavroulopoulos A, Aresti V, Zounis C. Right atrial thrombi complicating haemodialysis catheters. A meta-analysis of reported cases and a proposal of a management algorithm. Nephrol Dial Transplant. 2012;27(7):2936-2944.

22. Beregi JP, Aumegeat V, Loubeyre C, Coullet JM, Asseman P, Debacker-Steckelorom C, Bauchart JJ, et al. Right atrial thrombi: percutaneous mechanical thrombectomy. Cardiovasc Intervent Radiol. 1997;20(2):142145 . 